\title{
Water/Oil Cresting in Horizontal wells, A Sensitivity Study
}

\author{
Hector N. Akangbou*, Martin Burby, Ghasem Nasr \\ Petroleum Technology and Spray Research Groups, School of Computing \\ Science and Engineering, University of Salford, Manchester, United Kingdom, \\ M5 4WT. \\ Email: h.n.akangbou@edu.salford.ac.uk \\ Email:m.burby@salford.ac.uk \\ Email: g.g.nasr@salford.ac.uk \\ *Corresponding author
}

\begin{abstract}
This work presents a rigorous sensitivity analysis on cresting using a physical model, to investigate the effects of varying inclined section of horizontal well, lateral length in reservoir and oil viscosity on oil recovered, cumulative of water produced and Water Cut in thick- and thin-oil rim homogeneous reservoirs faced with strong bottom aquifer and considerable gas cap. From the results, it was observed that the geometry of the horizontal well and location of the bottom water injection points significantly influence the cumulative liquid produced, particularly in thin-oil rim reservoirs. The cumulative water produced and cumulative Water Cut were found to increase with increase in oil viscosity. The oil recovered from the thin-oil rim reservoir, were as high as $17.84 \%$ and $24.92 \%$ for oil viscosity of $50 \mathrm{cP}$ and $100 \mathrm{cP}$ respectively whereas $19.15 \%$ and $13.93 \%$ were observed for cumulative water produced from the thick-oil rim reservoir at $50 \mathrm{cP}$ and $100 \mathrm{cP}$ respectively.
\end{abstract}

\section{Keywords}

Cresting; oil recovery; Water Cut; reservoir homogeneity; horizontal wells; Gas-OilContact; Water-Oil-Contact; strong bottom aquifer; Pressure drawdown; optimization.

Biographical notes: Hector Ngozi Akangbou is a $\mathrm{PhD}$ candidate in the department of Petroleum and Gas Engineering, School of Computing Science and Engineering (CSE), University of Salford. Hector holds a BEng in Chemical Engineering from the University of Port Harcourt in Nigeria and a MSc. Degree in Petroleum and Gas Engineering from the University of Salford.

Martin Burby is a lecturer in the Petroleum and Gas Engineering Division and am programme leader for the Industrial and Commercial Combustion Engineering and Gas Engineering and Management programmes. I am also the Associate Head of the Spray 
Research Group (SRG). I graduated from the University of Salford with a BEng in Aeronautical Engineering and obtained an Engineering Doctorate from the University of Manchester. I have spent time both in industry and academia in the fields of combustion, spray research and new product development.

Ghasem Nasr is a full Professor with the Chair in Mechanical Engineering and Innovation in the School of Computing, Science and Engineering (CSE). I am Dean of Research and Innovation at the school of CSE. I have over 25 years academic and industrial experience, which encompasses research, innovation, development, commercial, and enterprise, curriculum development, management and resources. The group has collaborated and worked on various fundamental and applied research and development projects as well as building up innovation framework for over 120 multinational companies and educational establishments.

\section{Introduction}

Optimization of oil from oil reservoirs during cresting has been a major goal since the discovery of horizontal wells. Cresting like the name implies is a crest-like shape of effluents in an oil reservoir (Guo et al., 1992) occurring in horizontal wells. Cresting can be said to occur when the viscous force of the unwanted phase(s) exceeds the gravitational force and if equilibrium is not met, this can result in the influx of these unwanted fluids into the wellbore (Saad et al., 1995, Shadizadeh and Ghorbani, 2001, Smith and Pirson, 1963, Umnuayponwiwat and Ozkan, 2000). During cresting, the effluent(s) displace oil along its path, towards the perforation of the horizontal well. After water and or gas breakthrough, increasing ratios of the effluent(s) to oil increase over time (Singhal, 1993), which could lead to premature shut-in of the horizontal well and more money spent on Enhanced Oil Recovery (EOR) methods. The application of horizontal wells has yielded success in reducing cresting effect in both thick- and thinoil rim reservoirs when compared to conventional vertical wells due to more reservoir exposure of its lateral in the reservoir, thereby producing more oil at a given production rate (Hatzignatiou and Mohamed, 1994, Salavatov and Ghareeb, 2009). Modern industry practices to control this impairment to production are perforating wells as far above the oil Water-Oil-Contact (WOC) in water drive reservoirs, perforating low in the oil column away from the Gas-Oil-Contact (GOC) in gas cap drive reservoirs as well as producing below a critical rate (Salavatov and Ghareeb, 2009); a maximum oil flow rate at which water free oil and gas can be produced (Saad et al., 1995, Salavatov and Ghareeb, 2009, Shadizadeh and Ghorbani, 2001, Tarek, 2001). Producing at this rate or below, is widely considered uneconomical and at some point in the production cycle of the well, cresting will still occur due to the rise in oil-water and or gas-oil contact closer to the perforation of the well upon deletion of the reservoir (Leemhuis et al., 2007).

Nevertheless, most research have been focused on this critical rate, cresting control and effluent breakthrough times. Yang and Wattenbarger (1991) presented a correlation for water cresting to predict the critical rate, breakthrough time and Water-Oil-Ratio (WOR) after breakthrough in horizontal wells. Hatzignatiou and Mohamed (1994) developed a quite accurate correlation that can predict the breakthrough time for water and gas in vertical and horizontal wells. Menouar and Hakim (1995) numerically investigated the effect of some reservoir parameters (well length, anisotropy ratio, 
reservoir geometry and mobility ratio) on critical rate. Permadi (1996) further performed sensitivity on the effect of well placement and end point mobility ratio on the performance of horizontal well in a bottom water drive reservoir. They observed and concluded that these parameters strongly affect the performance of a horizontal well in a bottom water drive reservoirs. Water coning was numerically case-studied by Freeborn et al. (1990) in South Jenner pool, characterised by a thin-oil rim reservoir with thick bottom water. In their study, medium and long radii wells were drilled to determine their inflow performances compared to a vertical well in the presence of bottom water. Their result showed that production rate was highest for the long radius well. More so, Freeborn et al. (1990) numerically investigated different placement of the horizontal well from the top of the reservoir and observed that there was a decline in oil reserves produced and the closer the perforation of the well is to the WOC, the faster water cresting will occur due to the upward water flood provided by the bottom aquifer. More detailed research on cresting was reported by Makinde et al. (2011). In this paper, a rigorous sensitivity analysis will be performed to investigate the effect of varying inclined section (horizontal and vertical displacement) of horizontal wells, effect of lateral length in thick- and thin-oil rim homogeneous reservoirs with cresting problems.

\section{Experimental description and procedure}

The reservoir model depicted in Figure 1 illustrates the water and gas-cresting rig, made of clear acrylic, for effective cresting visibility. The reservoir used in this investigation was $0.45 \mathrm{~m}$ in length, $0.43 \mathrm{~m}$ in height and $0.10 \mathrm{~m}$ in width. For effective filling of porous media (polymer pellets) in the reservoir, the reservoir was assumed to have a free surface located at its top, through which gas cresting can also be modeled at atmospheric pressure. Due to the free surface, digital manometer pressure tapping was inserted at fixed centralized points, $0.18 \mathrm{~m}$ from top right and top left edges respectively and depth of $0.22 \mathrm{~m}$ in the reservoir. A vacuum initially at constant pressure of -4.351 Psig provided the pressure difference. Silicone oil, dyed red with viscosity of $50 \mathrm{cP}$ and $100 \mathrm{cP}$ were used in this study. Silicone oil was the preferred oil because it has noaffinity for water at the used pressure range (Pressure $\geq-4.351$ Psig).

Water inlet points 1 and 2 located at the bottom of the reservoir were for modeling bottom aquifer and ensuring uniform distribution during water injection. The density of the polymer pellet used was $>1200 \mathrm{~kg} / \mathrm{m}^{3}$, which was greater than the densest phase (fluorescein dyed water). The polymer pellets used were anisotropic but same-sized measuring $0.003 \mathrm{~m}$ by $0.002 \mathrm{~m}$ by $0.002 \mathrm{~m}$ in length, height and width respectively. The reservoir grain size was used instead of the conventional type (about 200 microns) in other to avoid the reservoir grains being sucked-up into the well and possibly produced with oil and water through the modeled horizontal well perforation sizes of $0.002 \mathrm{~m}$. Although the reservoir grain size and arrangement do not depict a conventional homogeneous reservoir, the modeled reservoir was considered homogeneous due to the same-sized reservoir grains and the high-interconnected pore spaces illustrated in the CT-Scan result of the sample reservoir grains (Figure 2a) illustrated in Figure 2b. The CT-Scan was performed using the General Electric (GE) Phoenix v $\mid$ tome $\mid \mathrm{x}$ s highresolution CT-Scanner. A total porosity of 0.191 was estimated for the homogeneous reservoir. The effective permeability of the reservoir grains to oil, water and gas were determined using Darcy's linear equation, with values obtained from steady state 
permeability test using the Fancher core/sample holder. The values of the effective permeability of the reservoir grains to oil, water and gas are summarized in Table 1. As shown in Figure 1, the horizontal well lateral length(s) in the reservoir were coupled to the inclined section(s) using compression fittings while the main bore is pneumatically fitted to the other end of the inclined section at angle(s) of inclination, with changes in True Vertical Depth (TVD) and horizontal displacements of the horizontal wells aided by an adjustable clamp. The radius and lengths of arcs for each horizontal well was determined using equation 1 . The dimensions of geometries for the horizontal wells are detailed in Table 2 and 3. In these tables, Cases $3 \mathrm{C}, 3 \mathrm{~B}$ and $2 \mathrm{C}$ were categorized based on estimated radius lengths as short radii wells, Cases-1A, 1B and 2A were considered as long radii whereas Cases-3A, $2 \mathrm{~B}$ and $1 \mathrm{C}$, medium radii wells.

$$
l=\left(n^{0} / 360^{\circ}\right) \times 2 \pi r
$$

Where $l$ is the length of arc in meters, $n^{o}$ is the angle of inclination in degrees, $r$ is the radius of arc in meters and $\pi=3.142$.

Figure 3 is a schematic of the horizontal well lateral placement in the reservoir. The lateral section of the horizontal well placement was closer to the GOC due to the strong nature of the bottom aquifer in order to delay the encroachment of unwanted water to the perforations of the horizontal well as well as achieve approximately the same breakthrough time for both water and gas. Although the lateral was positioned at the middle of the reservoir height $(0.225 \mathrm{~m})$, the lateral was $0.195 \mathrm{~m}$ from the WOC and $0.145 \mathrm{~m}$ from the GOC in thick-oil rim reservoir while for the thin-oil rim reservoir, the lateral was positioned at a distance, $0.125 \mathrm{~m}$ and $0.05 \mathrm{~m}$ from the WOC and GOC respectively.

\subsection{Procedure of rig operation}

The procedure for operation of the water and gas-cresting rig is as follows:

1. The first step was to set up the reservoir fluids. Dyed water was first pumped through the bottom water inlet points 1 and 2 to the required WOC. In this study, the WOC was varied at $0.03 \mathrm{~m}$ (thick-oil rim reservoir case) and $0.1 \mathrm{~m}$ (thin-oil rim reservoir case from the base of the reservoir. In other to achieve a rather uniform WOC, the oil was delivered across the top in little volumes at intervals. This procedure was continued until the desired GOC was reached. The modeled GOC was at $0.37 \mathrm{~m}$ (thick-oil rim reservoir case) and $0.28 \mathrm{~m}$ (thin-oil rim reservoir case) from the base of the reservoir. The oil was allowed enough time to settle for a precise contact height prior to start of experiment.

2. The vacuum pressure was then set at -4.351 Psig ensuring that the ball valve was at the close position during the pressure setting.

3. The water mass flow rate was set at $0.03 \mathrm{~kg} / \mathrm{s}$ during step 1 . A preliminary test was conducted to model a strong bottom aquifer. At -4.351 Psig the liquid production rate (approximately $0.01 \mathrm{~kg} / \mathrm{s}$ for all cases) was less than the water injection rate $(0.03 \mathrm{~kg} / \mathrm{s})$.

4. The ball valve for the water inlet was turned to the close position immediately 
the desired WOC was reached. At this point leakages were checked and fixed if any, prior to start of production while a digital timer was set at 0 second.

5. Production was started by turning the ball valve at the outlet completely to the open position, while synchronically starting the digital timer and turning on completely the ball valve for constant bottom water injection.

6. During production, the variation in pressure drop (difference between the pressure read from manometer and pressure from vacuum gauge) recorded until 495 seconds and 210 seconds for the thick and thin-oil rim reservoirs respectively.

7. For accuracy, each experimental case was repeated three times and the average liquid produced taken for each case. The error for each case illustrated in Figure 5 are as follows; Case-1A $( \pm 0.01 \%)$, Case-1B $( \pm 0.015 \%)$, Case-1C $( \pm 0.01 \%)$, Case-2A $( \pm 0.014 \%)$, Case-2B $( \pm 0.02 \%$,$) , Case-2C ( \pm 0.018 \%)$, Case-3A $( \pm 0.01 \%)$, Case-3B $( \pm 0.02 \%)$, and Case-3C $( \pm 0.013 \%)$. This was repeated for different lateral length in reservoir, oil viscosity, different inclined section (different horizontal well measured depth), WOC and GOC. In this investigation, capillarity at the inclined section due to the oil column height was considered negligible.

\section{Results and discussion}

The first step in investigating a problem is to first model the problem and as such Figure 4 shows the reservoir initially at its static condition (Figure $4 \mathrm{a}$ and $4 \mathrm{c}$ ) and at a production time step greater than 0 second (Figure $4 \mathrm{~b}$ and $4 \mathrm{~d}$ ) for lateral lengths in reservoir (lr), $0.251 \mathrm{~m}$ and $0.305 \mathrm{~m}$. A thin-oil rim reservoir was modeled with WOC and GOC, $0.1 \mathrm{~m}$ and $0.28 \mathrm{~m}$ respectively from the base of the reservoir whereas thickoil rim case was $0.03 \mathrm{~m}$ and $0.37 \mathrm{~m}$ for WOC and GOC respectively.

\subsection{Thick-oil rim reservoir}

\subsubsection{Effect of oil viscosity and lateral length on cumulative oil recovered}

Table 4 is a summary of the effect of change in oil viscosity and lateral length in the reservoir (lr) for all horizontal well cases in a thick-oil rim reservoir. Figure 5 is a plot of the experimental data shown in Table 4. Figure 5 shows that at a simulation time of 495 seconds, Case-3C a short medium radius well achieved the highest oil recovered from the reservoir at the same operating condition irrespective of the oil viscosity. On the contrary, Case-1A a long radius well performed worst. This is as a result of its longer measured depth when compared to other horizontal well cases, hence higher pressure drop along its entire length and lower flow velocity of reservoir fluid. However, the higher the viscosity of oil, the lower the oil production rate, as such the effect of viscosity on oil recovered is seen to decrease for all horizontal well cases in Figure 5. For all horizontal well cases, the shorter the lateral length in reservoir $(\mathrm{lr}=$ $0.251 \mathrm{~m}$ ), the higher the oil produced at the same operating condition. This was due to the longer diagonal-like movement of bottom aquifer with time towards the perforation of the shorter lateral well length in the reservoir, compared to the shorter vertical-like 
movement of the bottom aquifer experienced in horizontal wells with longer lateral length in the reservoir.

As shown in Figure 5, the shorter radii wells (Cases-2C 3B and 3C) had higher average oil recovered in all scenarios at the same production time when compared to medium and large radii wells. This was due to shorter overall well length accompanied by lower overall pressure drop during oil production, resulting in higher overall liquid withdrawal rate. Hence, the shortest radius well, Case 3C performed best in its category with 186.45E-04 and 151 E-04 Barrel (Bbl.) of oil recovered for longer lateral lengths in the reservoir, 232.78 E-04 and 176.32 E-04 Barrel for shorter lateral lengths in the reservoir. The shorter radius wells were found to be more effective in oil recovered from thick-oil rim reservoirs with higher oil viscosity (100 cP); 29.42\% and 26.51\% was estimated between the best and worst horizontal well cases whereas $8.93 \%$ and $17.84 \%$ was observed for oil viscosity of $50 \mathrm{cP}$.

\subsubsection{Effect of oil viscosity and lateral length on cumulative water produced}

The effect of increase in oil viscosity and lateral length in reservoir on the cumulative Water Cut and produced water in thick-oil rim reservoir is summarized in Table 5. Figure 6 illustrate a plot of all data in Table 5. Figure 6 shows that in all horizontal well cases increase in oil viscosity and reduction in lateral length in the reservoir results in increase in cumulative water produced.

In Table 5 and Figure 6, it can be seen that at the same lateral well length in reservoir and increase in oil viscosity, higher cumulative water produced was observed. In all horizontal well cases, it was observed that for an increase in oil viscosity from 50 to 100 $\mathrm{cP}$, the cumulative water produced increased approximately twice in Barrel of cumulative water produced. This was due to the lower oil velocity in the horizontal wells for higher oil viscosity, and as such resulted in significant increase in water influx especially after water breakthrough. As expected, the shorter radii horizontal wells had highest average cumulative water produced succeeded by the medium and long radii wells respectively, for different oil viscosity and lateral lengths in the reservoir. The higher overall pressure drop experienced in longer radii wells is the reason for the lower cumulative produced water. In all cases, the difference in cumulative produced water in percentage between the worst (Case-3C) and best case (Case-1A) was $19.15 \%$ for $50 \mathrm{cP}$ and longer lateral length in reservoir $(0.305 \mathrm{~m})$, succeeded by $13.93 \%$, (100 $\mathrm{cP}$ and $0.305 \mathrm{~m}$ lateral length in reservoir), $12.77 \%(50 \mathrm{cP}$ and $0.251 \mathrm{~m}$ lateral length in reservoir), and $9.42 \%$ (100 $\mathrm{cP}$ and $0.251 \mathrm{~m}$ lateral length in reservoir).

\subsubsection{Effect of oil viscosity and lateral length on cumulative Water Cut}

The histogram in Figure 7 depicts the graphical results shown in Table 6. Table 6 and Figure 7 represent the effect of change in oil viscosity and lateral length for thick-oil rim reservoir on cumulative Water Cut. As shown in Figure 7, the cumulative Water Cut increased with increase in oil viscosity and shorter lateral length in the reservoir in all horizontal well cases. In all horizontal well cases, the cumulative Water Cut is seen to be lowest for oil viscosity of $50 \mathrm{cP}$ and $\mathrm{lr}=0.305 \mathrm{~m}$ and highest in reservoir with 100 $\mathrm{cP}$ oil viscosity and $\mathrm{lr}=0.251 \mathrm{~m}$. 
Although the cumulative water produced increased with shorter well length in the reservoir, the cumulative Water Cut depended significantly on the cumulative oil recovered from the reservoir. Significant cumulative Water Cut values were observed in reservoirs with higher oil viscosity $(100 \mathrm{cP})$ and longer radii wells compared to short and medium radii wells. The unwanted water dominated production at post breakthrough times due to its lower viscosity compared to the oil, having higher oil mobility at the same operating pressure. Hence, the highest Water Cut was observed in Case-1C for oil viscosity of $100 \mathrm{cP}$ and shorter lateral $(0.251 \mathrm{~m})$ while the least was observed in Case-3A (oil viscosity of $50 \mathrm{cP}$ and long lateral length $0.305 \mathrm{~m}$ ). In addition, the total Cumulative Water Cut was found to be highest for long radii wells (708.86\%) while for medium and short radii wells the total Water Cut were $704.71 \%$ and $687.33 \%$ respectively.

\subsection{Thin-oil rim reservoir}

\subsubsection{Effect of oil viscosity and lateral length on cumulative oil recovered}

Table 7 summarizes the effect of change in oil viscosity and lateral length in the reservoir for all horizontal well cases in a thin-oil rim reservoir simulated at 210 seconds. A plot of the experimental data shown in Table 4 is illustrated in Figure 8. Figure 8 shows that at the same initial operating pressure, increase in oil viscosity results in reduction of oil recovered from the reservoir. More so, approximately twice the oil in Barrel is recovered for twice the oil viscosity. Figure 8 also shows that the short well length in reservoir for all horizontal well cases produced slightly more oil compared to the long lateral length. This was due to a shorter simulation time and obviously the longer horizontal displacement between the water injection point 2 (illustrated in Figure 1) and the perforations of the horizontal well. The diagonal shape of the crest towards the perforation of the horizontal wells is a major contributing factor. Figure 8 and Table 7 show that in this type of oil reservoirs (thin-oil rim reservoirs), Case-1C produced the lowest cumulative oil in all cases while Case- $2 \mathrm{C}$ a short radius well resulted in the highest oil recovered in all scenarios. This is possibly due to the geometry of the horizontal well, its inclined section (ratio of vertical displacement to the reservoir height), angle of inclination and its measured depth. The results presented in Figure 8 contradicts that presented by Freeborn et al. (1990). In their paper, numerical simulation was the method of study known to have higher percentage error due to assumptions compared to an experimental approach as presented in this paper. However, the reason for the poor performance of short radius well in their paper was stated to be due to different well completion and jet perforation issues, which has been bridged in this paper.

\subsubsection{Effect of oil viscosity and lateral length on cumulative water produced}

Table 8 summarizes the effect of increase in oil viscosity and change in lateral length in the reservoir in thin-oil rim reservoir. This was reported for cumulative water produced, represented graphically in Figure 9. Figure 9, shows that the cumulative water produced generally increase with increase in oil viscosity and reduced with reduction in length of lateral in the reservoir. 
As shown in Table 8 and Figure 9, at the same lateral well length in reservoir and increase in oil viscosity, higher cumulative water produced is observed in all horizontal well scenario. In all cases, twice the increase in oil viscosity resulted in approximately two times the cumulative water produced owing to lower oil velocity in the horizontal wells with increase in oil viscosity, at the same operating pressure. Figure 9 also show that at the same oil viscosity the cumulative water produced was independent of the measured depth of the horizontal well; although short radii horizontal wells are expected to have a rather higher water produced compared to long and medium radii well, this was not the case. The inconsistency in cumulative water produced experienced in the different horizontal wells was a function of the horizontal distance of the perforation from bottom water injection point 2 and oil viscosity for this kind of reservoirs. Hence, the short radii horizontal wells had least average cumulative water produced (329.17E-04 Barrel), succeeded with 336.18 E-04 and 337.78E-04 Barrel for long and medium radii wells respectively. The difference in percentage between the worst case (Case-1C) and best case (Case-2C) was $15.14 \%$ for $50 \mathrm{cP}$ and longer lateral length in reservoir $(0.305 \mathrm{~m}), 15.68 \%$ for $100 \mathrm{cP}$ and longer lateral length in reservoir $(0.305 \mathrm{~m})$ between Case-3C and $1 \mathrm{~A}, 15.81 \%$ for $50 \mathrm{cP}$ and short lateral length in reservoir $(0.251 \mathrm{~m})$ between Case-1C and Case-2C, and $12.11 \%$ for $100 \mathrm{cP}$ and longer lateral length in reservoir $(0.251 \mathrm{~m})$ between Case-1C and $2 \mathrm{C}$.

\subsubsection{Effect of oil viscosity and lateral length on cumulative Water Cut}

The histogram in Figure 10 illustrates the experimental data shown in Table 9. It can be seen in this figure that Water Cut generally increase with increase in oil viscosity and reduced with reduction in lateral length in reservoir. This is because unwanted water dominates production after breakthrough and due to its lower viscosity compared to the oil, higher volumes of water influx is expected. However, the shorter lateral well length in reservoir did not always result in higher cumulative Water Cut in all horizontal well scenarios. The cumulative Water Cut is seen to be lowest $(24.53 \%)$ in Case-3C due to higher initial oil production rate (higher velocity of the oil flow due to lower oil viscosity) while the highest cumulative Water Cut was observed in Case-3A (77.10\%) due to lower initial oil production rate. Hence, the cumulative Water Cut depends on the oil recovered and cumulative water produced.

\subsection{Effect of lateral length on pressure drop}

Tables 10 and 11 are summaries of the experimental data for pressure drop in Figure 11. Figure 11 illustrates the effect of lateral length on pressure drop versus time for Cases$1 \mathrm{~A}, 1 \mathrm{C}, 3 \mathrm{C}$ and $2 \mathrm{~A}$. Figures $11 \mathrm{a}$ and $11 \mathrm{~b}$ illustrate pressure drop results for Cases-1A and $1 \mathrm{C}$ in thick-oil rim reservoir. As expected, Figure 11a, shows that pressure drop generally decrease with increase in simulation time. However, at the same initial operating pressure, slightly higher-pressure drops were experienced for the longer lateral length in the reservoir $(1 \mathrm{r}=0.305 \mathrm{~m})$ due to longer measured depths in the horizontal well cases. Figure $11 \mathrm{~b}$ shows the pressure drop versus production time for Case-1C. In this figure a similar trend to that depicted in Figure 11a was observed. Hence, lower pressure drop at production time steps was observed for the short lateral length in the reservoir $(\mathrm{lr}=0.251 \mathrm{~m})$. 
Figure 11c and 11d illustrate pressure drop results in thin-oil rim reservoir for Cases-3C and $2 \mathrm{~A}$. In both figures, the pressure drop decreased with simulation time. The shorter the lateral length in the reservoir in both cases (Cases-3C and 2A) produced liquid at a slightly higher pressure drop compared to the long lateral length for the same operating pressure and oil viscosity $(50 \mathrm{cP})$. Figures $11 \mathrm{a}$ to $11 \mathrm{~b}$, show that the thin-oil rim cases had lower pressure drop at stop of production compared to thick-oil rim reservoirs due to the faster depletion of reservoir pressure from the high effluent(s) produced and hence shorter simulation time required for these kind of reservoirs, thereby achieving very high Water Cut values at shorter simulation times.

\section{Conclusion}

In this study, rigorous sensitivity analyses were performed involving varying lengths of inclined sections, Water-Oil-Contacts, Gas-Oil-Contacts, lateral lengths in reservoir. From these analyses, it was concluded that:

1. The shorter the measured depth of horizontal wells, the higher the cumulative water produced irrespective of the oil viscosity. At post breakthrough, the cumulative water produced depends on the measured depth of the horizontal well.

2. Experimentally, the cumulative water produced and oil recovered for horizontal wells depend on the location of the bottom water injection points. The farther the horizontal displacement from the farthest injection point, the lower the cumulative water produced at the same operating pressure and liquid production time.

3. The shape of the water and gas crest depends on the location of the horizontal well perforations and distance of the lateral well length in the reservoir. Due to the shorter simulation time required for thin-oil rim reservoirs, shorter lateral length in reservoir attain lower cumulative water produced owing to the diagonal-like movement of water crest towards the perforation of the horizontal well.

4. Short radii wells are recommended for application in reservoirs with cresting problems. Shorter radii wells are characterized by higher liquid withdrawal rate; higher volumes of water produced but lower Water Cut. Performance of horizontal wells depends on the geometry and measured depth of the horizontal well.

5. Thin-oil rim reservoirs reach incredibly high Water Cut and cumulative water produced values in a shorter production time unlike thick-oil rim reservoirs at the same operating condition.

6. Reservoir Engineers can better understand how production can be effectively optimized in oil reservoirs affected by cresting problem, using the procedure outlined in this paper. 


\section{References}

Akangbou, H.N., Burby, M., Nasr, G. (2017) 'Effectively optimizing production of horizontal wells in homogeneous oil reservoirs'. Journal of Petroleum Science and Engineering, Vol.150, pp.128-136. doi:10.1016/j.petrol.2016.12.005.

Freeborn, W. R., Russell, B. and Macdonald, A. J. (1990) 'South Jenner Horizontal Wells A Water Coning Case Study'. Petroleum Society of Canada, doi: 10.2118/90-03-04.

Guo, B., Molinard, J. E. and Lee, R. L. (1992) 'A General Solution of Gas/Water Coning Problem for Horizontal Wells'. Society of Petroleum Engineers, doi: $10.2118 / 25050-\mathrm{MS}$.

Hatzignatiou, D. G. and Mohamed, F. (1994) 'Water And Gas Coning In Horizontal And Vertical Wells'. Petroleum Society of Canada, doi: 10.2118/94-26.

Leemhuis, A. P., Belfroid, S. and Alberts, G. (2007) 'Gas Coning Control for Smart Wells'. Society of Petroleum Engineers, doi: 10.2118/110317-MS.

Makinde, F. A., Adefidipe, O. A. and Craig, A. J. (2011) 'Water Coning in Horizontal Wells: Prediction of Post-Breakthrough Performance'. International Journal of Engineering \& Technology IJET-IJENS, Vol: 11 No: 01.

Menouar, H. K. and Hakim, A. A. (1995) 'Water Coning And Critical Rates In Vertical And Horizontal Wells'. Society of Petroleum Engineers, doi: 10.2118/29877MS.

Permadi, P. (1996) 'Fast Horizontal-Well Coning Evaluation Method'. Society of Petroleum Engineers, doi: 10.2118/37032-MS.

Saad, S. E.-D. M., Darwich, T. D. and Asaad, Y. (1995) 'Water Coning in Fractured Basement Reservoirs'. Society of Petroleum Engineers, doi: 10.2118/29808-MS.

Salavatov, T. S. and Ghareeb, A. (2009) 'Predicting the behaviour of water and gas coning in horizontal wells'. Oil and Gas Business. http://www.ogbus.ru/eng/authors/Salavatov/Salavatov_1.pdf (Accessed 10 September 2016).

Shadizadeh, S. R. and Ghorbani, D. (2001) 'Investigation of Water/Gas Coning in Natural Fractured Hydrocarbon Reservoirs'. Petroleum Society of Canada, doi: 10.2118/2001-014.

Singhal, A. K. (1993) 'Water And Gas Coning/Cresting - A Technology Overview'. Petroleum Society of Canada, doi: 10.2118/SS-93-31.

Smith, C. R. and Pirson, S. J. (1963) 'Water Coning Control in Oil Wells by Fluid Injection'. Society of Petroleum Engineers, doi: 10.2118/613-PA.

Tarek, A. (2001) 'Reservoir Engineering Handbook', $2^{\text {nd }}$ Ed., pp. 574.

Umnuayponwiwat, S. and Ozkan, E. (2000) 'Water and Gas Coning toward FiniteConductivity Horizontal Wells: Cone Buildup and Breakthrough'. Society of Petroleum Engineers, doi: 10.2118/60308-MS.

Yang, W. and Wattenbarger, R. A. 1991. 'Water Coning Calculations for Vertical and Horizontal Wells'. Society of Petroleum Engineers, doi: 10.2118/22931-MS. 
Table 1 Reservoir Data

\begin{tabular}{cc}
\hline Parameters & Values \\
\hline Viscosity of Silicone oil (cP) & 50,100 \\
Viscosity of water (cP) & 1.004 \\
Effective permeability to Silicone oil (D) & 1.06 \\
Effective permeability to gas (D) & 4.41 \\
Effective permeability to water (D) & 2.93 \\
\hline
\end{tabular}

Table 2 Geometry and dimensions of horizontal wells [E-01 (m)]

\begin{tabular}{|c|c|c|c|c|c|c|c|c|}
\hline \multirow[t]{2}{*}{ Cases } & \multirow{2}{*}{$\begin{array}{l}\text { Angle of } \\
\text { inclination } \\
\text { (Degrees) }\end{array}$} & \multicolumn{2}{|c|}{$\begin{array}{c}\text { Measured } \\
\text { Depth (MD) }\end{array}$} & \multirow[t]{2}{*}{ TVD } & \multicolumn{2}{|c|}{$\begin{array}{l}\text { Build section } \\
\text { Measurement }\end{array}$} & \multirow[t]{2}{*}{$\begin{array}{l}\text { Main } \\
\text { bore }\end{array}$} & \multirow{2}{*}{$\begin{array}{c}\text { Lateral } \\
\text { length } \\
\text { outside } \\
\text { reservoir }\end{array}$} \\
\hline & & $\mathrm{MD}_{1}$ & $\mathrm{MD}_{2}$ & & $\mathrm{~V}_{\mathrm{d}}$ & $\mathrm{H}_{\mathrm{d}}$ & & \\
\hline Case-1A & 15 & 7.18 & 6.64 & 2.17 & 0.77 & 1.02 & 1.40 & 1.68 \\
\hline Case-1B & 23 & 7.01 & 6.47 & 2.03 & 0.63 & 0.93 & 1.40 & 1.68 \\
\hline Case-1C & 30 & 6.90 & 6.36 & 1.94 & 0.54 & 0.85 & 1.40 & 1.68 \\
\hline Case-2A & 15 & 6.83 & 6.29 & 1.90 & 0.50 & 0.80 & 1.40 & 1.68 \\
\hline Case-2B & 23 & 6.76 & 6.22 & 1.87 & 0.47 & 0.78 & 1.40 & 1.68 \\
\hline Case-2C & 30 & 6.64 & 6.10 & 1.74 & 0.34 & 0.73 & 1.40 & 1.68 \\
\hline Case-3A & 15 & 6.48 & 5.94 & 1.72 & 0.32 & 0.49 & 1.40 & 1.68 \\
\hline Case-3B & 23 & 6.40 & 5.86 & 1.69 & 0.29 & 0.44 & 1.40 & 1.68 \\
\hline Case-3C & 30 & 6.34 & 5.80 & 1.67 & 0.27 & 0.41 & 1.40 & 1.68 \\
\hline
\end{tabular}

Table 3 Geometry and dimensions of horizontal wells continued [E-01 (m)]

\begin{tabular}{|c|c|c|c|c|c|c|c|}
\hline \multicolumn{2}{|c|}{$\begin{array}{l}\text { Length of horizontal } \\
\text { lateral section }(\mathrm{LH})\end{array}$} & \multirow[t]{2}{*}{$\begin{array}{l}\text { Distance } \\
\text { between } \\
\text { perforation }\end{array}$} & \multirow{2}{*}{$\begin{array}{c}\text { Distance from } \\
\text { bridge block to } \\
\text { first } \\
\text { perforation }\end{array}$} & \multicolumn{2}{|c|}{$\begin{array}{l}\text { Length of lateral } \\
\text { inside reservoir } \\
\text { (lr) }\end{array}$} & \multirow[t]{2}{*}{$\begin{array}{l}\text { Arc } \\
\text { length }\end{array}$} & \multirow[t]{2}{*}{$\begin{array}{l}\text { Arc } \\
\text { radius }\end{array}$} \\
\hline $\mathrm{LH}_{1}$ & $\mathrm{LH}_{2}$ & & & $\operatorname{lr}_{1}$ & $1 r_{2}$ & & \\
\hline 4.19 & 4.73 & 0.50 & 0.40 & 3.05 & 2.51 & 1.05 & 4.02 \\
\hline 4.19 & 4.73 & 0.50 & 0.40 & 3.05 & 2.51 & 0.88 & 2.23 \\
\hline 4.19 & 4.73 & 0.50 & 0.40 & 3.05 & 2.51 & 0.78 & 1.49 \\
\hline 4.19 & 4.73 & 0.50 & 0.40 & 3.05 & 2.51 & 0.70 & 2.68 \\
\hline 4.19 & 4.73 & 0.50 & 0.40 & 3.05 & 2.51 & 0.63 & 1.59 \\
\hline 4.19 & 4.73 & 0.50 & 0.40 & 3.05 & 2.51 & 0.51 & 0.98 \\
\hline 4.19 & 4.73 & 0.50 & 0.40 & 3.05 & 2.51 & 0.35 & 1.34 \\
\hline 4.19 & 4.73 & 0.50 & 0.40 & 3.05 & 2.51 & 0.27 & 0.70 \\
\hline 4.19 & 4.73 & 0.50 & 0.40 & 3.05 & 2.51 & 0.21 & 0.40 \\
\hline
\end{tabular}


Table 4 Effect of oil viscosity and lateral length on oil recovered at 495 seconds production time for thick-oil rim reservoir (E-04) (Bbl.).

\begin{tabular}{ccccc}
\hline Cases & $\begin{array}{c}\text { Oil recovered } \\
{[50 \mathrm{cP}, \mathrm{lr}} \\
(0.305 \mathrm{~m})]\end{array}$ & $\begin{array}{c}\text { Oil recovered } \\
{[100 \mathrm{cP}, \mathrm{lr}} \\
(0.305 \mathrm{~m})]\end{array}$ & $\begin{array}{c}\text { Oil recovered } \\
{[50 \mathrm{cP}, \mathrm{lr}} \\
(0.251 \mathrm{~m})]\end{array}$ & $\begin{array}{c}\text { Oil recovered } \\
{[100 \mathrm{cP}, \mathrm{lr}} \\
(0.251 \mathrm{~m})]\end{array}$ \\
\hline Case-1A & 170.85 & 107.24 & 192.53 & 129.57 \\
Case-1B & 171.56 & 108.07 & 193.16 & 129.70 \\
Case-1C & 173.13 & 109.63 & 194.98 & 131.40 \\
Case-2A & 169.80 & 113.15 & 191.40 & 134.99 \\
Case-2B & 176.81 & 120.00 & 198.66 & 142.10 \\
Case-2C & 184.26 & 127.36 & 206.43 & 150.19 \\
Case-3A & 172.31 & 139.31 & 219.07 & 162.92 \\
Case-3B & 183.06 & 149.69 & 229.35 & 173.08 \\
Case-3C & 186.45 & 151.95 & 232.78 & 176.32 \\
\hline
\end{tabular}

Table 5 Effect of oil viscosity and lateral length in reservoir on cumulative water produced at 495 seconds (E-04) (Bbl.)

\begin{tabular}{ccccc}
\hline Cases & $\begin{array}{c}\text { Cumulative } \\
\text { water produced } \\
{[50 \mathrm{cP}, \mathrm{lr}} \\
(0.305 \mathrm{~m})]\end{array}$ & $\begin{array}{c}\text { Cumulative } \\
\text { water produced } \\
{[100 \mathrm{cP}, \mathrm{lr}} \\
(0.305 \mathrm{~m})]\end{array}$ & $\begin{array}{l}\text { Cumulative } \\
\text { water produced } \\
{[50 \mathrm{cP}, \mathrm{lr}} \\
(0.251 \mathrm{~m})]\end{array}$ & $\begin{array}{l}\text { Cumulative } \\
\text { water produced } \\
{[100 \mathrm{cP}, \mathrm{lr}} \\
0.251 \mathrm{~m})]\end{array}$ \\
\hline Case-1A & 125.97 & 197.21 & 240.04 & 336.42 \\
Case-1B & 129.15 & 201.23 & 243.98 & 340.11 \\
Case-1C & 132.50 & 204.16 & 249.18 & 345.56 \\
Case-2A & 134.76 & 206.67 & 251.78 & 348.16 \\
Case-2B & 137.61 & 210.53 & 255.05 & 351.18 \\
Case-2C & 143.73 & 216.90 & 261.59 & 357.89 \\
Case-3A & 148.93 & 222.01 & 267.71 & 363.93 \\
\hline Case-3B & 149.60 & 222.76 & 268.63 & 364.85 \\
Case-3C & 155.80 & 229.13 & 275.17 & 371.39 \\
\hline
\end{tabular}


Table 6 Effect of oil viscosity and lateral length on cumulative Water Cut in percentage at 495 seconds

\begin{tabular}{ccccc}
\hline Cases & $\begin{array}{c}\text { Cumulative Water } \\
\text { Cut }[50 \mathrm{cP}, \mathrm{lr} \\
(0.305 \mathrm{~m})]\end{array}$ & $\begin{array}{c}\text { Cumulative Water } \\
\text { Cut }[100 \mathrm{cP}, \mathrm{lr} \\
(0.305 \mathrm{~m})]\end{array}$ & $\begin{array}{c}\text { Cumulative } \\
\text { Water Cut }[50 \\
\mathrm{cP}, \operatorname{lr}(0.251 \mathrm{~m})]\end{array}$ & $\begin{array}{c}\text { Cumulative } \\
\text { Water Cut }[100 \\
\mathrm{cP}, \mathrm{lr}(0.251 \mathrm{~m})]\end{array}$ \\
\hline Case-1A & 42.44 & 64.78 & 55.49 & 72.20 \\
\hline Case-1B & 42.95 & 65.06 & 55.81 & 72.39 \\
Case-1C & 43.35 & 65.06 & 56.10 & 72.45 \\
Case-2A & 44.25 & 64.62 & 56.81 & 72.06 \\
Case-2B & 43.77 & 63.7 & 56.21 & 71.19 \\
Case-2C & 43.82 & 63.00 & 55.89 & 70.44 \\
Case-3A & 46.36 & 61.44 & 56.00 & 69.08 \\
\hline Case-3B & 44.97 & 59.81 & 53.94 & 67.83 \\
Case-3C & 45.52 & 60.13 & 54.17 & 67.81 \\
\hline
\end{tabular}

Table 7 Effect of oil viscosity and lateral length on oil recovered at 210 seconds (E-04) (Bbl.)

\begin{tabular}{ccccc}
\hline Cases & $\begin{array}{c}\text { Oil } \\
\text { recovered } \\
{[50 \mathrm{cP}, \mathrm{lr}} \\
(0.305 \mathrm{~m})]\end{array}$ & $\begin{array}{c}\text { Oil } \\
\text { recovered } \\
{[100 \mathrm{cP}, \mathrm{lr}} \\
(0.305 \mathrm{~m})]\end{array}$ & $\begin{array}{c}\text { Oil } \\
\text { recovered } \\
{[50 \mathrm{cP}, \mathrm{lr}}\end{array}$ & $\begin{array}{c}\text { Oil } \\
\text { recovered } \\
{[100 \mathrm{cP}, \mathrm{lr}}\end{array}$ \\
\hline Case-1A & 60.19 & 36.16 & 61.01 & 36.80 \\
Case-1B & 61.01 & 37.10 & 61.95 & 37.87 \\
\hline Case-1C & 52.71 & 30.69 & 53.40 & 31.33 \\
\hline Case-2A & 61.58 & 39.50 & 62.33 & 40.05 \\
Case-2B & 53.78 & 31.76 & 54.09 & 32.51 \\
\hline Case-2C & 62.96 & 41.00 & 65.10 & 43.58 \\
\hline Case-3A & 55.04 & 33.08 & 55.98 & 34.78 \\
\hline Case-3B & 61.64 & 39.68 & 62.58 & 40.32 \\
\hline Case-3C & 61.91 & 40.05 & 63.21 & 40.82 \\
\hline
\end{tabular}


Table 8 Effect of oil viscosity and lateral length on cumulative water produced at 210 seconds (E-04) (Bbl.)

\begin{tabular}{ccccc}
\hline Cases & $\begin{array}{c}\text { Cumulative } \\
\text { water } \\
\text { produced } \\
{[50 \mathrm{cP}, \mathrm{lr}} \\
(0.305 \mathrm{~m})]\end{array}$ & $\begin{array}{c}\text { Cumulative } \\
\text { water } \\
\text { produced } \\
{[100 \mathrm{cP}, \mathrm{lr}} \\
(0.305 \mathrm{~m})]\end{array}$ & $\begin{array}{c}\text { Cumulative } \\
\text { water } \\
\text { produced } \\
{[50 \mathrm{cP}, \mathrm{lr}} \\
(0.251 \mathrm{~m})]\end{array}$ & $\begin{array}{c}\text { Cumulative } \\
\text { water } \\
\text { produced } \\
{[100 \mathrm{cP}, \mathrm{lr}} \\
0.251 \mathrm{~m})]\end{array}$ \\
\hline Case-1A & 70.40 & 95.54 & 69.56 & 94.54 \\
Case-1B & 71.74 & 97.13 & 70.90 & 96.05 \\
Case-1C & 74.17 & 99.56 & 73.67 & 98.98 \\
\hline Case-2A & 72.49 & 101.40 & 71.74 & 97.05 \\
Case-2B & 72.16 & 110.37 & 71.66 & 96.63 \\
\hline Case-2C & 62.94 & 111.38 & 62.02 & 86.99 \\
\hline Case-3A & 63.95 & 100.90 & 62.86 & 87.41 \\
\hline Case-3B & 65.21 & 112.55 & 64.45 & 89.17 \\
Case-3C & 65.80 & 113.30 & 64.95 & 89.76 \\
\hline
\end{tabular}

Table 9 Effect of oil viscosity and lateral length on cumulative Water Cut at 210 seconds in percentage

\begin{tabular}{ccccc}
\hline Cases & $\begin{array}{c}\text { Cumulative } \\
\text { Water Cut [50 } \\
\text { cP, lr } \\
(0.305 \mathrm{~m})]\end{array}$ & $\begin{array}{c}\text { Cumulative } \\
\text { Water Cut }[100 \\
\mathrm{cP}, \mathrm{lr} \\
(0.305 \mathrm{~m})]\end{array}$ & $\begin{array}{c}\text { Cumulative } \\
\text { Water Cut [50 } \\
\text { cP, }, \mathrm{lr} \\
(0.251 \mathrm{~m})]\end{array}$ & $\begin{array}{c}\text { Cumulative } \\
\text { Water Cut }[100 \\
\text { cP, }, \mathrm{lr} \\
(0.251 \mathrm{~m})]\end{array}$ \\
\hline Case-1A & 53.91 & 72.54 & 53.27 & 71.98 \\
Case-1B & 54.04 & 72.36 & 53.37 & 71.72 \\
Case-1C & 58.46 & 76.44 & 57.98 & 75.96 \\
Case-2A & 54.07 & 71.97 & 53.51 & 70.79 \\
Case-2B & 57.30 & 76.06 & 56.99 & 74.83 \\
Case-2C & 50.00 & 72.91 & 48.79 & 66.62 \\
Case-3A & 53.74 & 77.10 & 52.90 & 71.54 \\
Case-3B & 51.41 & 73.93 & 50.74 & 68.86 \\
Case-3C & 24.53 & 73.88 & 50.68 & 68.74 \\
\hline
\end{tabular}


Table 10 Effect of lateral length on pressure drop for thick-oil rim reservoir at 495 seconds (E-01) (Psig)

\begin{tabular}{ccccc}
\hline $\begin{array}{c}\text { Time } \\
\text { (seconds) }\end{array}$ & $\begin{array}{c}\text { Case-1A } \\
{[50 \mathrm{cP}, \mathrm{lr}} \\
(0.305 \mathrm{~m})]\end{array}$ & $\begin{array}{c}\text { Case-1A } \\
{[50 \mathrm{cP}, 1 \mathrm{r}} \\
0.251 \mathrm{~m})]\end{array}$ & $\begin{array}{c}\text { Case-1C } \\
{[50 \mathrm{cP}, \mathrm{lr}}\end{array}$ & $\begin{array}{c}\text { Case-1C } \\
{[50 \mathrm{cP}, \mathrm{lr}}\end{array}$ \\
\hline 0 & 43.37 & 43.37 & 43.37 & $43.37 \mathrm{~m})]$ \\
\hline 150 & 42.21 & 41.63 & 41.63 & 40.9 \\
300 & 40.61 & 38.58 & 40.32 & 38.00 \\
450 & 36.99 & 33.5 & 36.41 & 33.07 \\
495 & 33.36 & 30.46 & 32.92 & 27.12 \\
\hline
\end{tabular}

Table 11 Effect of lateral length on pressure drop for thin-oil rim reservoir at 210 seconds (E-01) (Psig)

\begin{tabular}{ccccc}
\hline $\begin{array}{c}\text { Time } \\
\text { (seconds) }\end{array}$ & $\begin{array}{c}\text { Case-3C } \\
{[50 \mathrm{cP}, \mathrm{lr}} \\
(0.305 \mathrm{~m})]\end{array}$ & $\begin{array}{c}\text { Case-3C } \\
{[50 \mathrm{cP}, \mathrm{lr}} \\
0.251 \mathrm{~m})]\end{array}$ & $\begin{array}{c}\text { Case-2A } \\
{[50 \mathrm{cP}, \mathrm{lr}} \\
0.305 \mathrm{~m})]\end{array}$ & $\begin{array}{c}\text { Case-2A } \\
{[50 \mathrm{cP}, \mathrm{lr}} \\
0.251 \mathrm{~m})]\end{array}$ \\
\hline 0 & 43.37 & 43.37 & 43.37 & 43.37 \\
50 & 39.16 & 39.16 & 40.47 & 40.03 \\
100 & 38.44 & 38.44 & 40.18 & 39.74 \\
150 & 38 & 37.42 & 39.45 & 38.87 \\
210 & 35.97 & 34.63 & 37.28 & 36.14 \\
\hline
\end{tabular}


Figure 1 Water and gas cresting rig (after Akangbou et al. 2017)

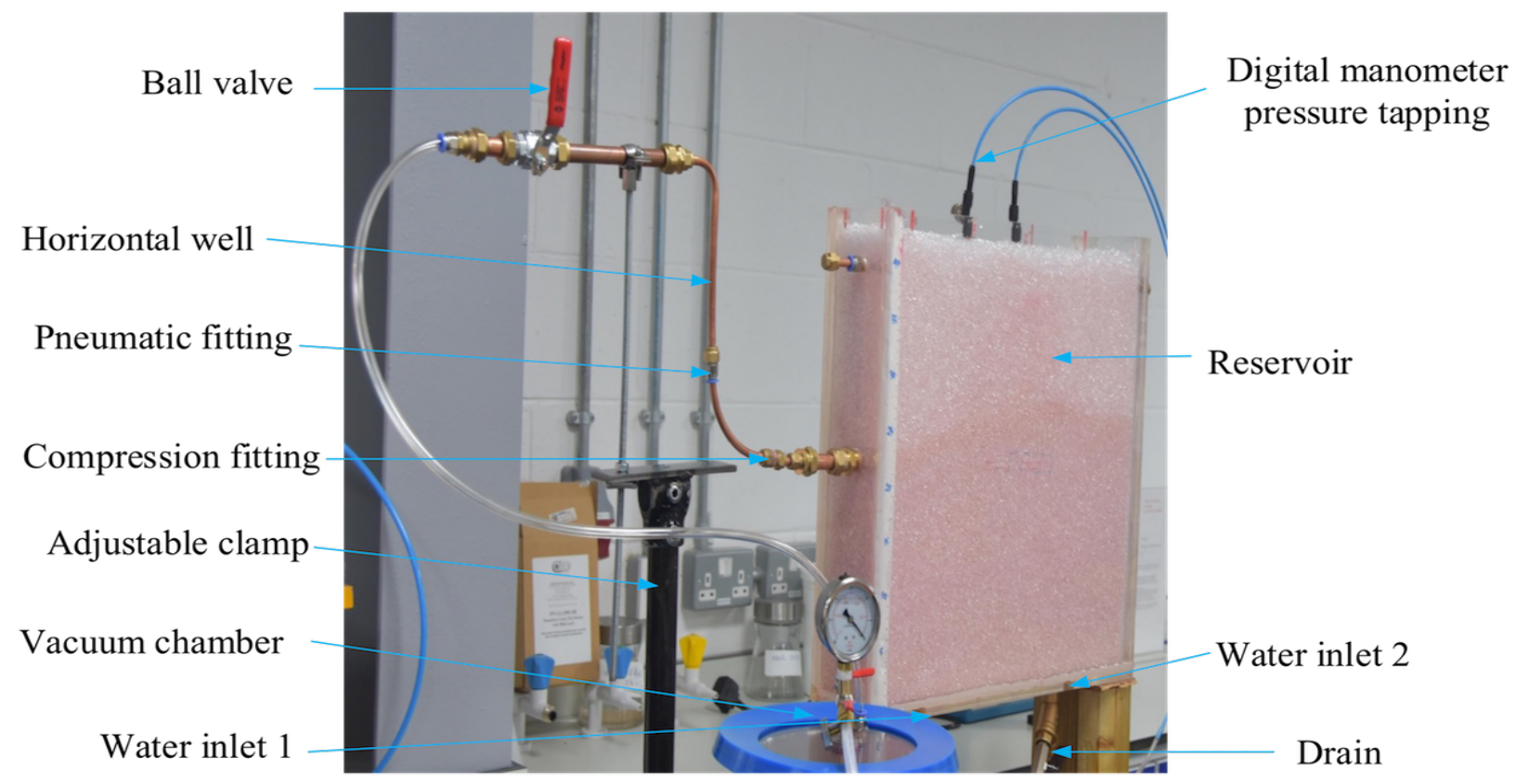

Figure 2 (a) Sample of reservoir grains (b) processed sample showing interconnected pore spaces

(a)

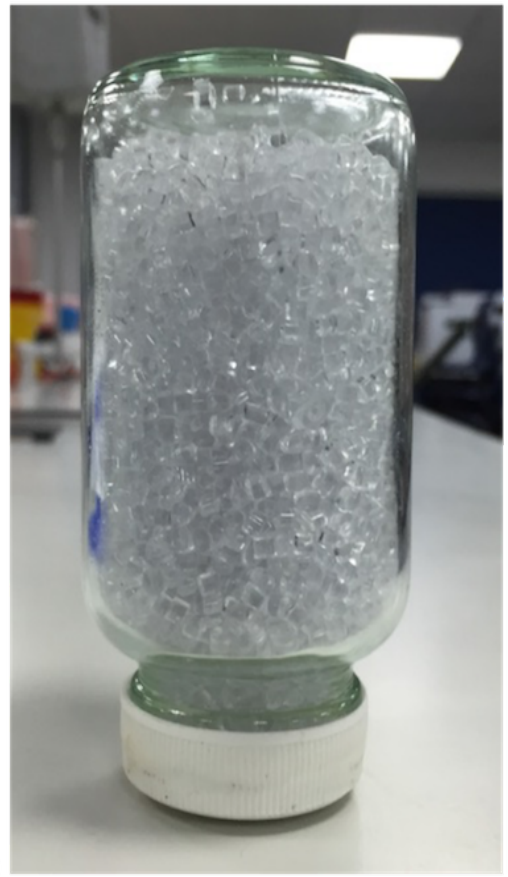

(b)

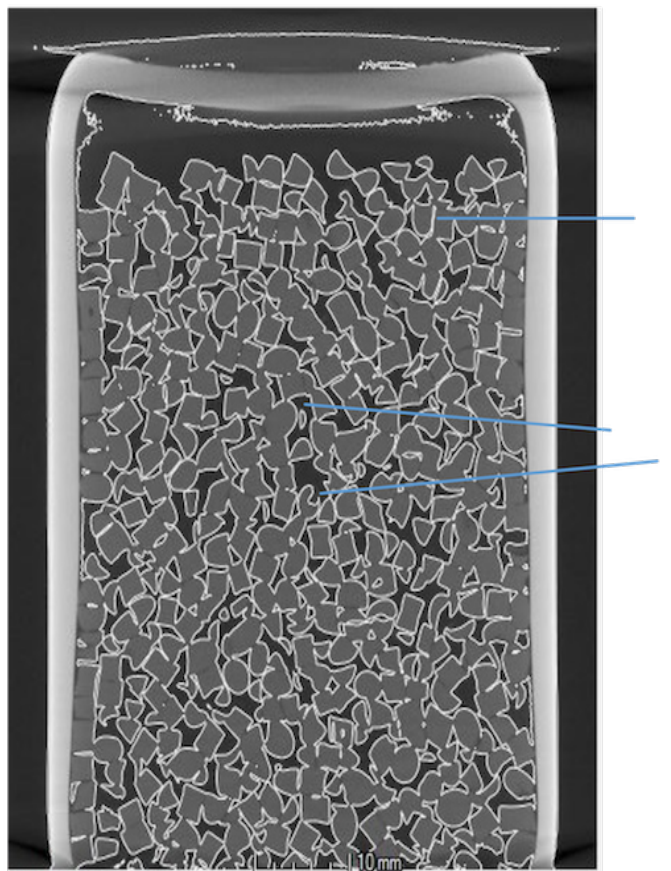

Reservoir

grains

Interconnected pore spaces 
Figure 3 A schematic showing horizontal well lateral placement in reservoir

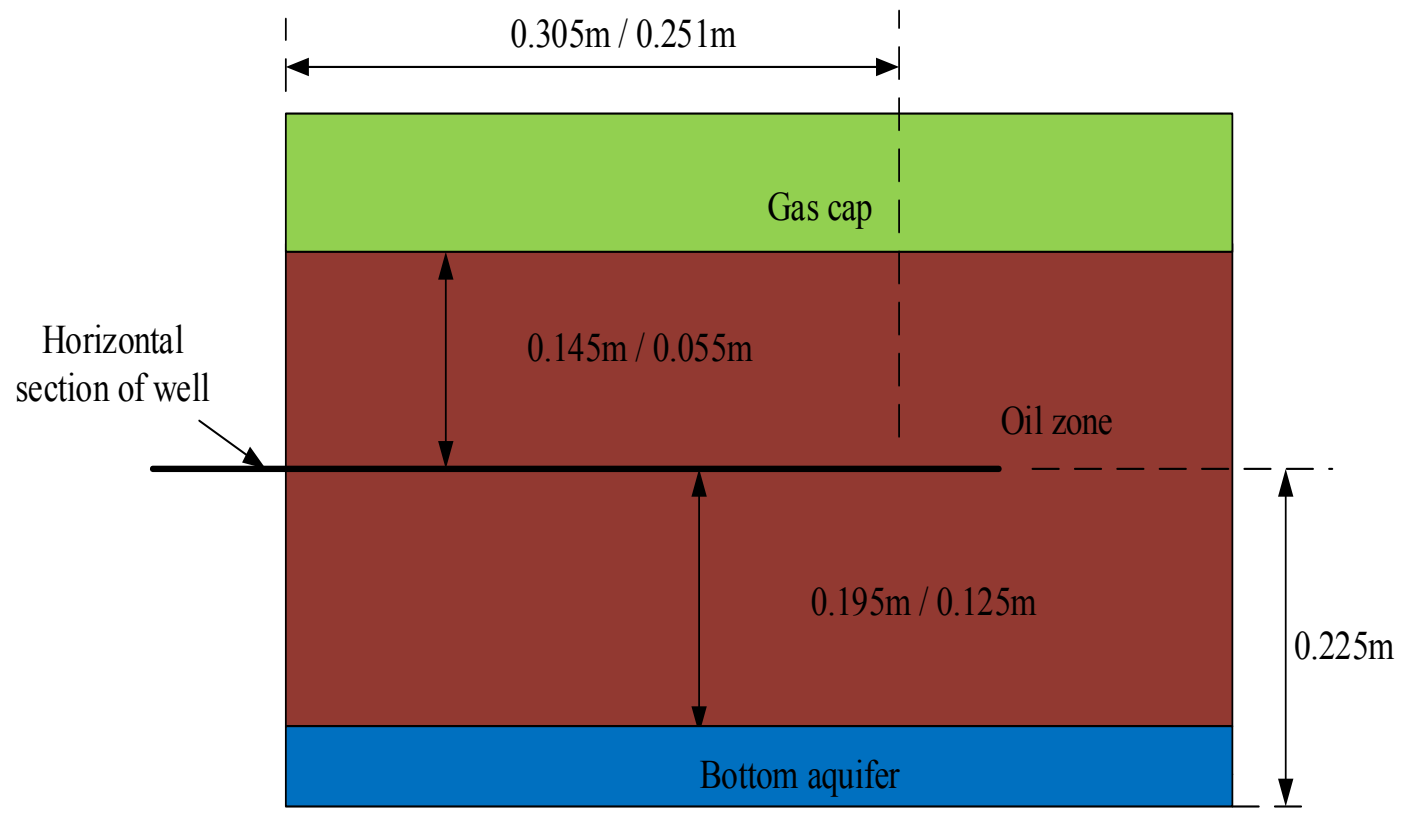

Figure 4 (a) thick-oil rim reservoir at static condition $(\mathrm{lr}=0.305 \mathrm{~m})(\mathrm{b})$ thick-oil rim reservoir at time $>0$ second $((\mathrm{lr}=0.305 \mathrm{~m}$ (c) thin-oil rim reservoir at static condition ( $\mathrm{lr}$ $=0.251 \mathrm{~m})(\mathrm{d})$ thin-oil rim reservoir at time $>0$ second $((\mathrm{l}=0.251 \mathrm{~m})$
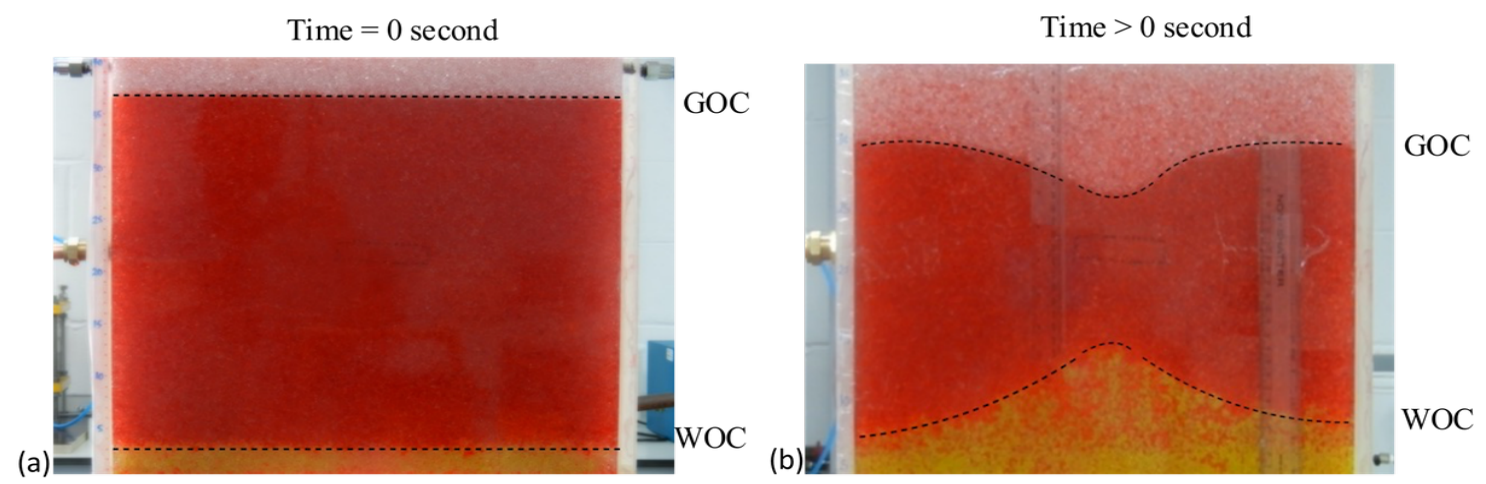

Time $=0$ second

Time $>0$ second
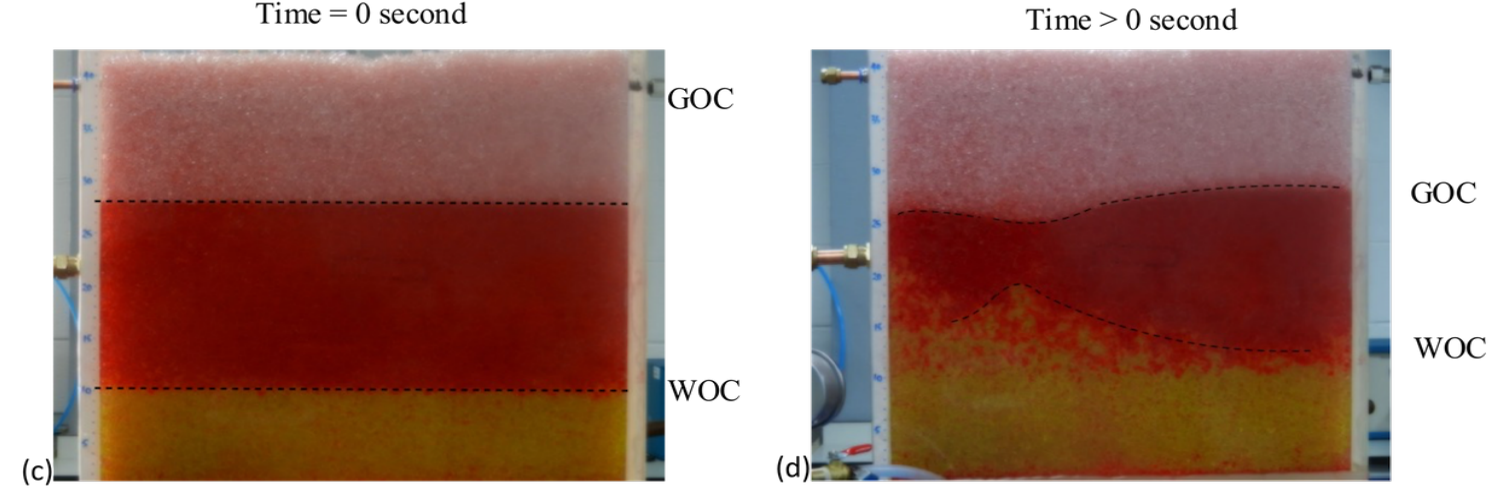
Figure 5 Effect of oil viscosity and lateral length on oil recovered at 495 seconds

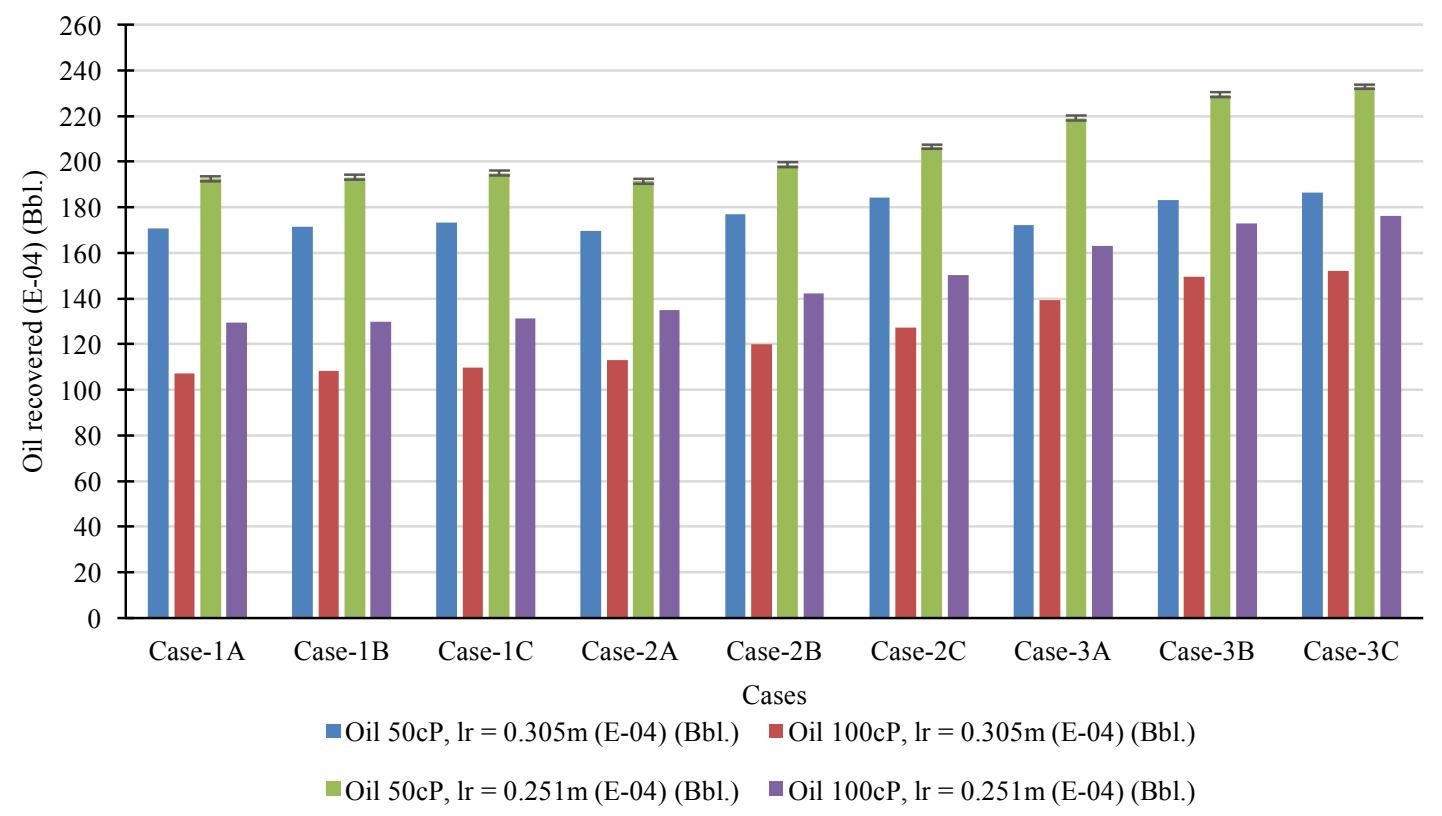

Figure 6 Effect of oil viscosity and lateral length on cumulative water produced at 495 seconds

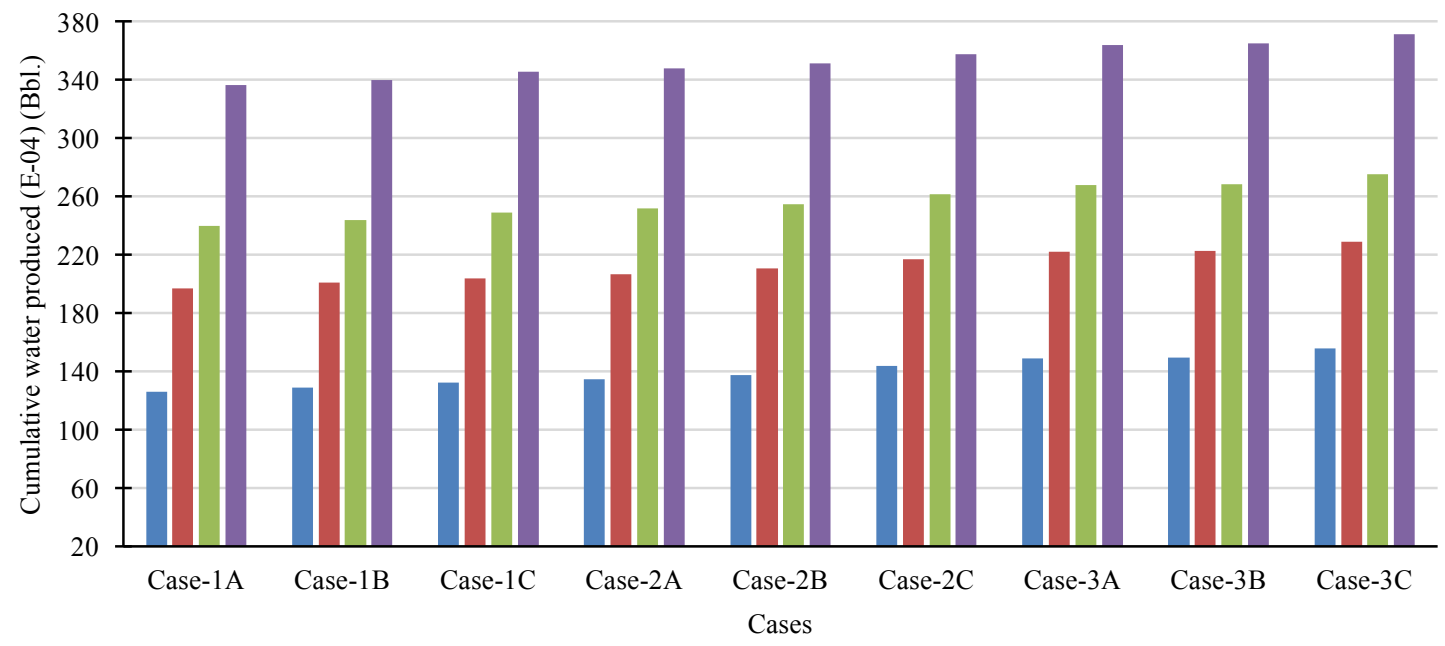

- Cumulative water produced 50cP, $1 \mathrm{r}=0.305 \mathrm{~m}(\mathrm{E}-04)(\mathrm{Bbl}) \quad \square$ Cumulative water produced 100cP, $1 \mathrm{r}=0.305 \mathrm{~m}(\mathrm{E}-04)(\mathrm{Bbl})$

Cumulative water produced $50 \mathrm{cP}, \mathrm{lr}=0.251 \mathrm{~m}(\mathrm{E}-04)(\mathrm{Bbl}$.$) \quad Cumulative water produced 100 \mathrm{cP}, 1 \mathrm{r}=0.251 \mathrm{~m}(\mathrm{E}-04)(\mathrm{Bbl}$. $)$ 
Figure 7 Effect of oil viscosity and lateral length on cumulative Water Cut at 495 seconds

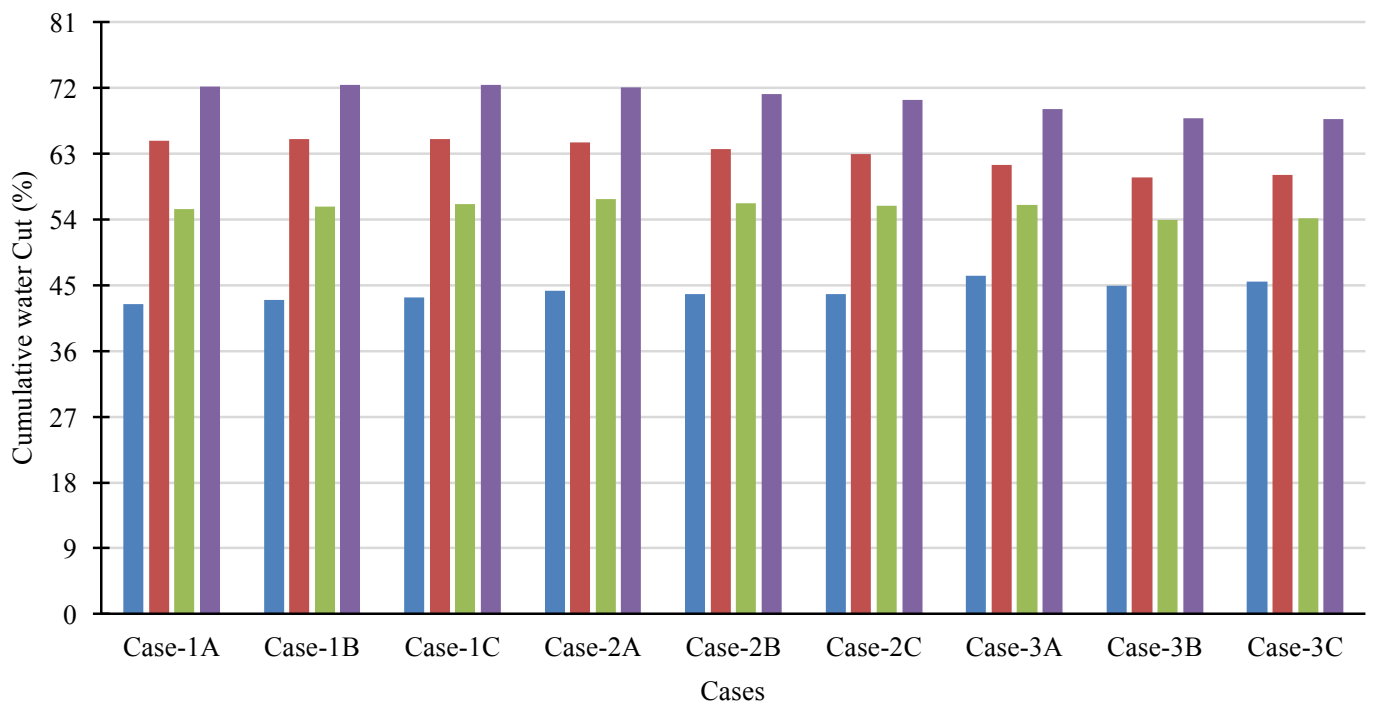

- Cumulative Water Cut $50 \mathrm{cP}, 1 \mathrm{r}=0.305 \mathrm{~m}(\mathrm{E}-04)$

Cumulative Water Cut $100 \mathrm{cP}, 1 \mathrm{r}=0.305 \mathrm{~m}(\mathrm{E}-04)$

- Cumulative Water Cut $50 \mathrm{cP}, \mathrm{lr}=0.251 \mathrm{~m}(\mathrm{E}-04)$

- Cumulative Water Cut $100 \mathrm{cP}, \mathrm{lr}=0.251 \mathrm{~m}(\mathrm{E}-04)$

Figure 8 Effect of oil viscosity and lateral length on oil recovered at 210 seconds

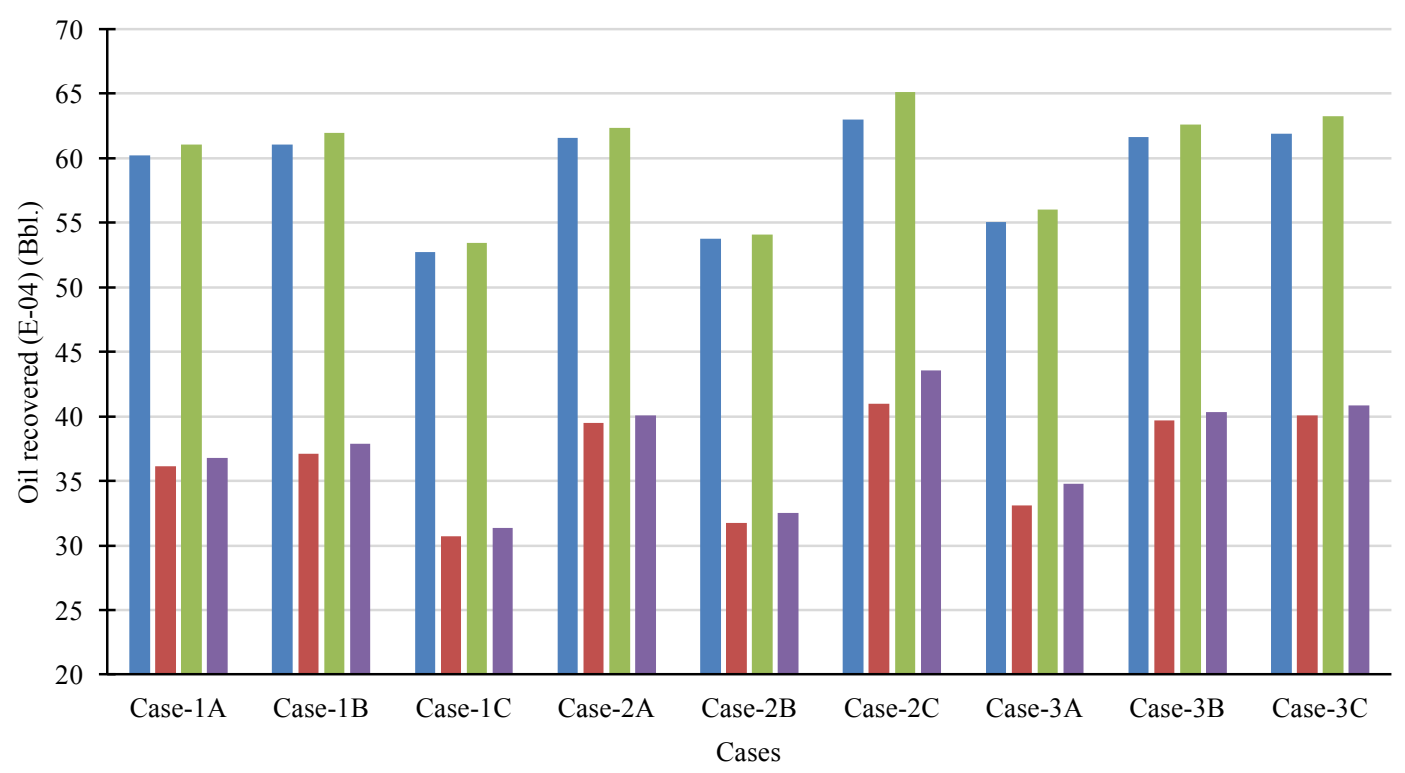

Oil 50cP, $1 \mathrm{r}=0.305 \mathrm{~m}(\mathrm{E}-04)(\mathrm{Bbl}) \quad \square$ Oil $100 \mathrm{cP}, \mathrm{r}=0.305 \mathrm{~m}(\mathrm{E}-04)(\mathrm{Bbl}$.

Oil 50cP, $1 \mathrm{r}=0.251 \mathrm{~m}(\mathrm{E}-04)(\mathrm{Bbl}) \quad$ Oil 100cP, $1 \mathrm{r}=0.251 \mathrm{~m}(\mathrm{E}-04)(\mathrm{Bbl}$. 
Figure 9 Effect of oil viscosity and lateral length on cumulative water produced at 210 seconds

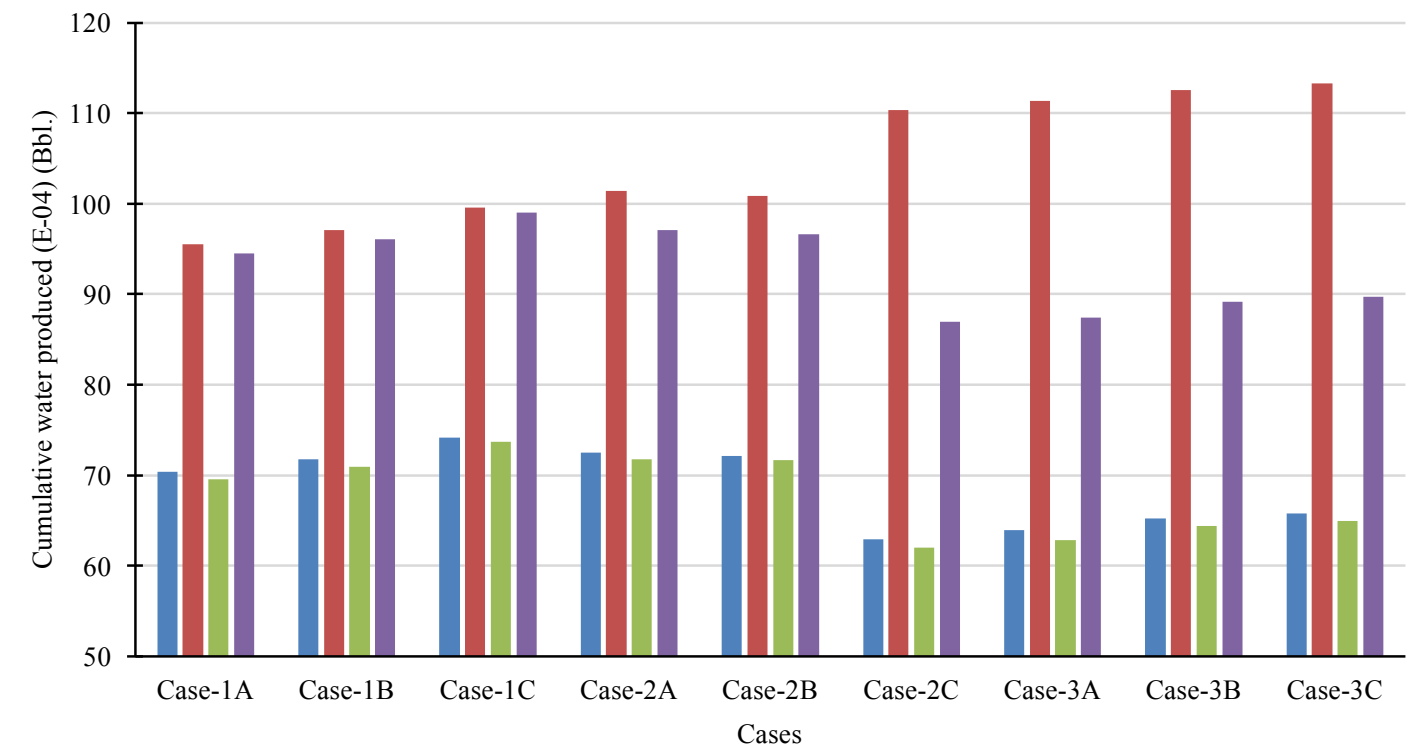

Cumulative water produced 50cP, $1 \mathrm{r}=0.305 \mathrm{~m}(\mathrm{E}-04)(\mathrm{Bbl}) \quad$ Cumulative water produced $100 \mathrm{cP}, 1 \mathrm{r}=0.305 \mathrm{~m}(\mathrm{E}-04)(\mathrm{Bbl}$.

Cumulative water produced $50 \mathrm{cP}, 1 \mathrm{r}=0.251 \mathrm{~m}(\mathrm{E}-04)(\mathrm{Bbl}) \quad \square$ Cumulative water produced $100 \mathrm{cP}, 1 \mathrm{r}=0.251 \mathrm{~m}(\mathrm{E}-04)(\mathrm{Bbl})$

Figure 10 Effect of oil viscosity and lateral length on cumulative Water Cut at 210 seconds

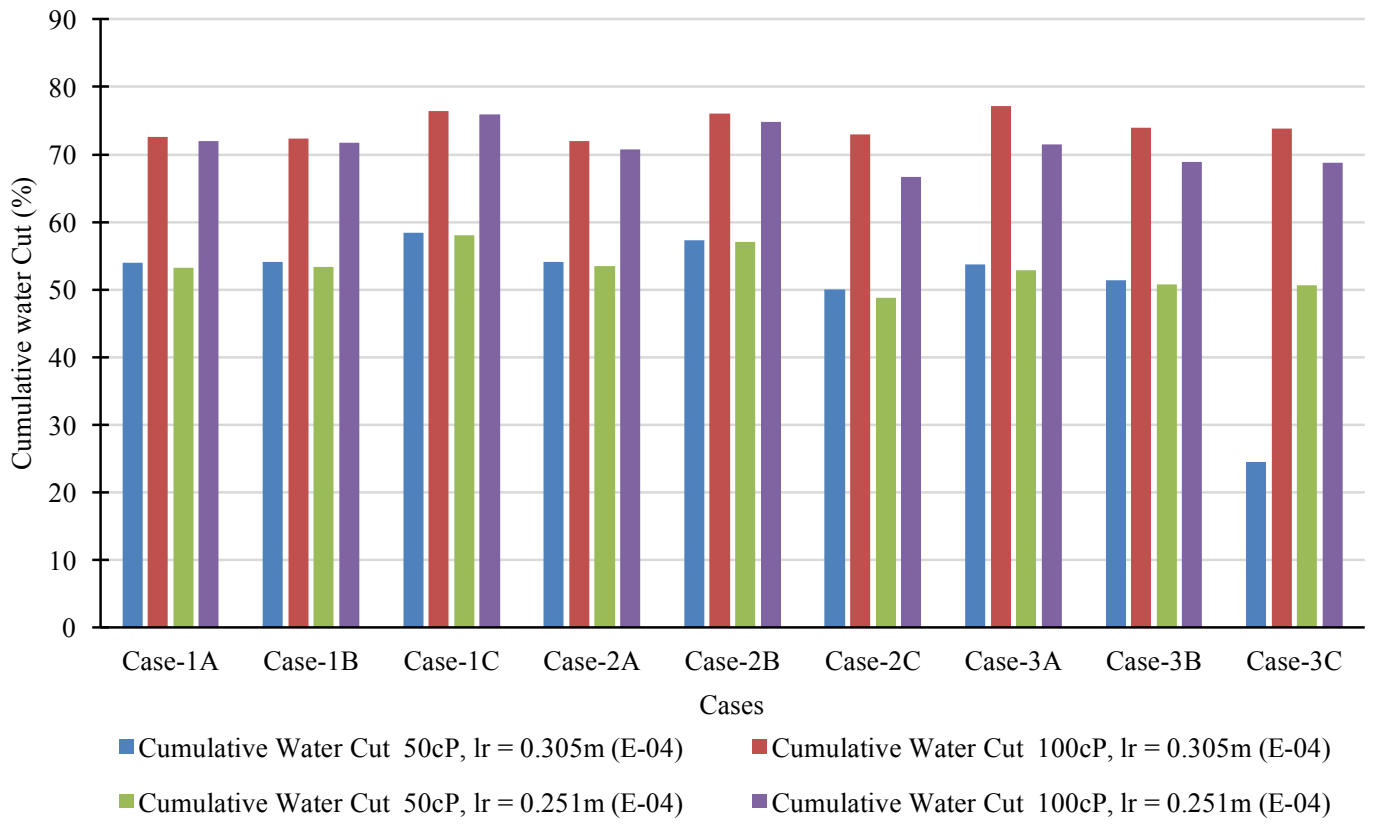


Figure 11 Effect of lateral length on pressure drop for thick-oil rim reservoir at 495 seconds [(a) Cases-1A and (b) Case-1C], 210 seconds [(c) Cases-3C and (d) Case-2A)]

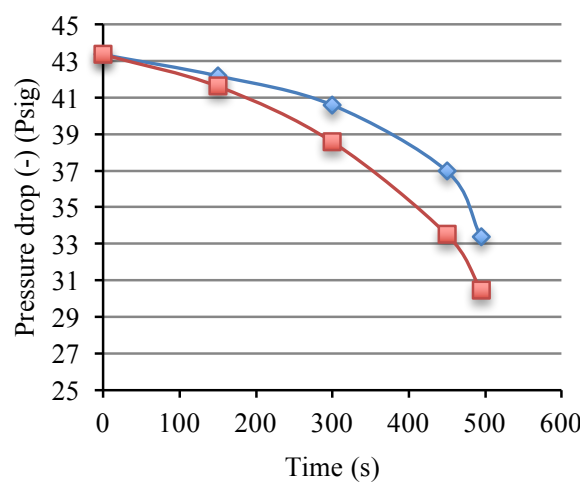

$\neg$ Case-1A (E-01) (Psig) $(50 \mathrm{cP}, 1 \mathrm{r}=0.305 \mathrm{~m})$ $\longrightarrow$ Case-1A (E-01) (Psig) $(50 \mathrm{cP}, \mathrm{lr}=0.251 \mathrm{~m})$

(a)

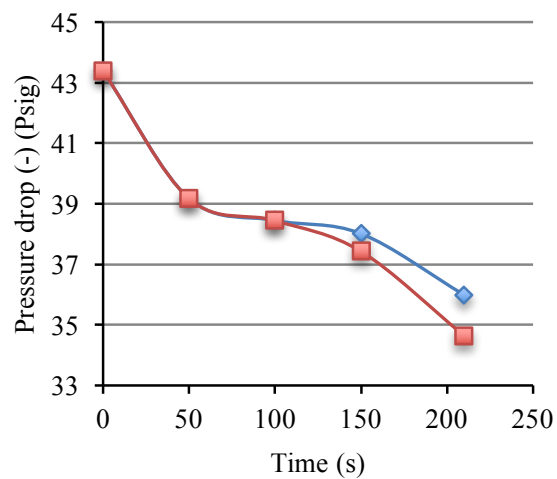

$\sim$ Case-3C (E-01) (Psig) $(50 \mathrm{cP}, 1 \mathrm{r}=0.305 \mathrm{~m})$

(c)

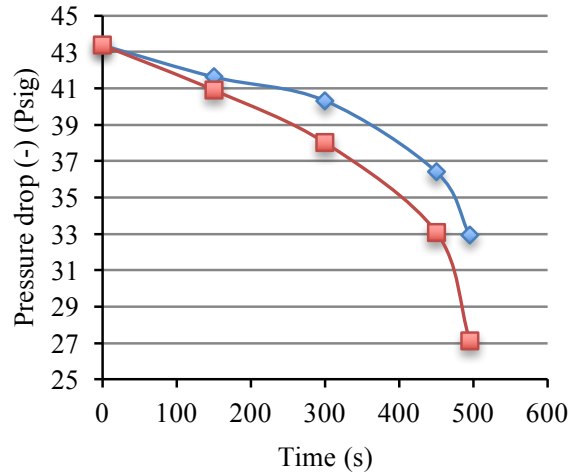

$\leadsto$ Case-1C (E-01) (Psig) $(50 \mathrm{cP}, 1 \mathrm{r}=0.305 \mathrm{~m})$ $\longrightarrow$ Case-1C (E-01) (Psig) (50cP, lr = 0.251m)

(b)

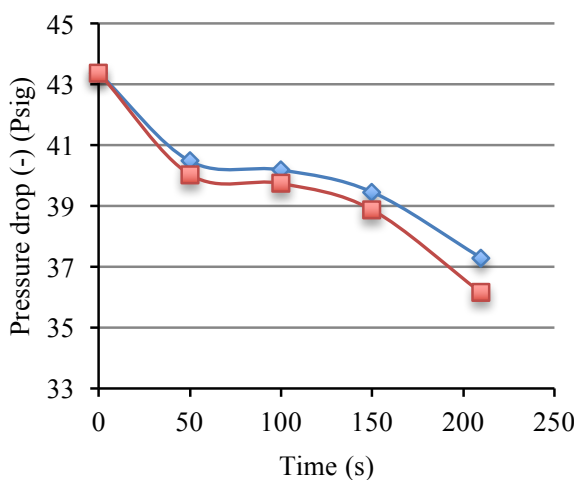

$\multimap$ Case-2A (E-01) (Psig) $(50 \mathrm{cP}, 1 \mathrm{r}=0.305 \mathrm{~m})$

(d) 